\title{
La política exterior canadiense: una identidad propia que se consolida
}

$\mathrm{E}$ $\mathrm{n}$ Rise to globalism de los estadounidenses Stephen Ambrose y Douglas Brinkley, sólo se menciona a Canadá en un párrafo: el que se refiere a la firma del Tratado de Libre Comercio de América del Norte, en donde se señala que Canadá es el destino de la tercera parte de las inversiones estadounidenses en el extranjero (Ambrose y Brinkley 1997: 369-370). Punto. Nada más. Este hecho no deja de ser sorprendente, pues el libro ha sido considerado un "clásico", una pieza clave, no sólo como introducción al estudio de la política exterior de Estados Unidos sino también de las relaciones internacionales contemporáneas.

Los autores hacen un sustancioso recuento de los grandes acontecimientos históricos desde el fin de la Segunda Guerra Mundial; se habla de las potencias más importantes, de los grandes temas de la agenda internacional... México, por ejemplo, es mencionado al menos tres veces; se lleva al menos seis páginas en el análisis de su política exterior con respecto a América Latina y otras referencias que con mucho trascienden el TLCAN. Canadá no va más allá de dicho párrafo.

Después de leer tan importante pieza bibliográfica, es un tanto extraño que Canadá, siendo una de las siete mayores potencias económicas del planeta, no haya tenido un papel histórico más visible en sus relaciones con el exterior. Tres explicaciones aventuradas serían: 1) Canadá es una nación tan identificada con el interés estadounidense que el estudio de su política exterior no ameritaría mayor diferenciación con respecto a la de su vecino del sur; 2) Canadá es un país que, a pesar de

* Profesor investigador del Departamento de Estudios Internacionales. Maestro en Relaciones Internacionales, School of Advanced International Studies, John Hopkins University. su grandeza económica, simplemente no ha estado históricamente interesado en aventurarse en el exterior más allá de lo que otra nación de tamaño mediano haría; o 3 ) Canadá ha sido siempre un país subordinado a las decisiones que se toman en Washington, DC.

En este ensayo veremos que estas percepciones, que por desgracia alguna vez llegaron incluso a convertirse en fuertes prejuicios, aunque sí alcanzan a capturar algunas características de la política exterior canadiense, ya no son del todo válidas a principios del siglo xxi. Canadá comienza a tener una actitud más dinámica, más asertiva y segura de sí misma en la escena internacional, que exige nuevos conceptos e ideas para describir su política exterior.

Desde el punto de vista histórico, la política exterior canadiense sin duda dependió de la forma en que su vecino, económicamente más fuerte y militarmente más dinámico, ha ejercido sus relaciones internacionales. El interés histórico estadounidense por anexarse Canadá nació mucho antes de la independencia de las trece colonias, y la sola idea de que Canadá pudiera ser un jugoso botín fue uno de los motivos contundentes para ir a la guerra en julio de 1812 contra Inglaterra, la nación más fuerte del planeta por ese entonces. Este interés no se diluyó sino hasta después de la guerra civil estadounidense y la compra de Alaska en 1867, cuando nuevos mercados, más que territorios, fueron la prioridad para los líderes estadounidenses (Lafeber, 1989).

No debemos olvidar que algunos grupos canadienses, sobre todo del occidente del país, veían con agrado el proyecto de unir sus regiones a Estados Unidos, pues la popularidad del régimen inglés decaía rápidamente en el 
transcurso del siglo xIx. Eso explicaría en parte la actitud de los líderes canadienses un tanto discreta y conservadora al relacionarse con el mundo en general y con Estados Unidos en particular: por más de cien años, un pequeño descuido diplomático y varios líderes estadounidenses no hubieran dudado por un minuto en seguir presionando por la anexión.

El año de 1867 fue también muy importante para los canadienses. El parlamento inglés aprobó el "Acta de Norteamérica" en la que oficialmente se le daba "autonomía" a las provincias de Canadá, pero que de facto le otorgaba independencia al país. Desde 1867 hasta el fin de la Segunda Guerra Mundial tanto Estados Unidos como Canadá gozaron de niveles muy altos de industrialización y desarrollo económico. El siglo xx fue de indudables convergencias en las vidas de estas dos potencias. Ambos países descubrieron que el desarrollo económico en forma independiente de su vecino no tenía sentido. Por otra parte, ambos participaron en las dos guerras mundiales defendiendo ideales, valores e intereses muy similares. Los dos influyeron decisivamente en el diseño y posterior puesta en marcha del sistema económico internacional de corte liberal, así como del sistema político de la posguerra. Los dos fueron y son el pilar no-europeo de la Organización del Tratado del Atlántico Norte (OTAN).

Por supuesto, no todo fue convergencia y solidaridad mutua en el caso de la agenda bilateral. El punto más álgido se dio sobre todo en la década de los setenta. Durante la administración Nixon, Estados Unidos impuso fuertes tarifas arancelarias que afectaron a Canadá más que a cualquier otro país, pues a él se destinaba el $70 \%$ de las exportaciones canadienses. Está también el caso de graves conflictos políticos cuando Canadá permitió la entrada (y no exigía la salida) de varones estadounidenses que huían del ingreso obligatorio al servicio de las fuerzas armadas. A pesar de estos fuertes desacuerdos y conflictos de intereses, Canadá mostró continuidad en su apoyo hacia la política exterior de su vecino del sur durante la mayor parte del siglo xx.

Sin embargo, los últimos quince años han sido testigos del cambio de dirección que los canadienses han ejercido en su relación con otras naciones: dirección que no siempre ha coincidido con la estadounidense y que refleja el papel que los líderes canadienses consideran que su país debe tomar. Cuatro áreas en especial pueden ilustrar el papel más dinámico y asertivo que Canadá está jugando en la actualidad:

\section{Política hacia el Pacífico y el APEC}

$\mathrm{Al}$ igual que con México antes de la firma del TLCAN, no es un secreto que más que oportunidades, Canadá percibe a los países de la Cuenca del Pacífico como fuertes competidores en su mercado por excelencia: Estados Unidos. Sin embargo, empieza a aceptarse entre los círculos oficiales la idea de "complementación", más que de "competencia" con la ribera del $\mathrm{Pa}$ cífico. Canadá, al igual que Estados Unidos, además de ser consumidor e importador de bienes finales, es un innovador y creador de tecnología de punta, que los países asiáticos sin duda adquirirán para dar mayor empuje a su desarrollo industrial, el cual con toda seguridad estará basado en tecnologías más limpias. Estas ideas encontradas obligan a los líderes canadienses a diseñar estrategias amplias que consideren tanto a los opositores como a los optimistas de un APEC más fuerte. Para implementar estas estrategias los canadienses han tenido que meterse de lleno a labores de cabildeo y de negociación con los países miembros del APEC, dejando a un lado actitudes pasivas que podrían ir en contra de sus intereses (Minden et al., 1997). 
Con respecto al desarrollo político en la ribera del Pacífico, fue en Canadá, no en Estados Unidos, donde se originaron las voces norteamericanas más fuertes y contundentes que condenaron la masacre de la Plaza de Tiananmen, China, en 1989 y que de forma decisiva influyeron en la opinión pública estadounidense y en los círculos de Washington (Chan, 1997).

\section{América Latina}

Con el retorno de la idea del "continentalismo" y con una participación más activa en la Organización de Estados Americanos (OEA), a partir de la década de los noventa Canadá plantea estrategias novedosas en la forma en como las relaciones hemisféricas deben llevarse a cabo (Stephenson, 2000). Algunas de ellas se consideran más completas para el desarrollo de Latinoamérica que aquellas comúnmente propuestas por el vecino del sur: el desarrollo regional, por ejemplo, requiere una estrategia que incluya al libre comercio, pero el libre comercio en sí mismo no es la panacea a los problemas económicos de América Latina. Cada vez más las universidades, las organizaciones no gubernamentales y las oficinas del gobierno federal se adentran al tema del desarrollo internacional como campo en el que Canadá puede aportar ideas frescas.

\section{La otan y el frente común contra el terrorismo internacional}

Inmediatamente después de los ataques del 11 de septiembre, el gobierno llevó a cabo la mayor movilización militar en su historia y la primera desde el fin de la Segunda Guerra Mundial, con el objetivo de proteger sus fronteras, mostrar su solidaridad a su vecino del sur y echar mano del sistema de seguridad colectivo de la otan. Por ser un aliado indiscutible de Estados Unidos, los líderes canadienses percibieron con acierto la vulnerabilidad de su país ante un ataque terrorista. Pero también concluyeron correctamente que el terrorismo es una plaga internacional, no un fenómeno aislado en el que hay víctimas propias de un solo país.

\section{Irak y Medio O riente}

Saddam Hussein y su régimen dictatorial nunca fueron populares en Canadá, mucho menos a partir de la Guerra del Golfo Pérsico en 1991. Sin embargo, eso no impidió que tanto la opinión pública como los líderes canadienses se opusieran a la forma (mas no a la sustancia) en cómo se definió y se resolvió el problema iraquí en la administración de George W. Bush. Desde un principio los canadienses, que al igual que los mexicanos tenían un lugar en el Consejo de Seguridad de las Naciones Unidas como miembro no permanente durante el conflicto, se opusieron a una intervención militar unilateral por parte de la administración Bush. Sin pruebas contundentes de la existencia de armas de destrucción masiva y programas para desarrollarlas, Canadá fue uno de los pioneros en prever que un consenso amplio en la comunidad internacional para lograr un plan o una estrategia al menos legítima, si no legal, sería muy difícil de lograr.

Estas cuatro áreas de acción muestran tanto los intereses como las expectativas actuales de los canadienses en sus relaciones con el exterior. Aunque hay temas en que sus intereses y preferencias convergen con los estadounidenses, no necesariamente tiene que ser siempre así. Asimismo, demuestran que Canadá actúa ya como un país maduro que lleva a cabo una política exterior más segura de sí misma y que refleja una identidad más genuina.

\section{Referencias bibliográficas}

Ambrose, Stephen E. y Douglas G. Brinkley (1997) Rise to globalism. Penguin Books: Baskerville.

Doran, Charles (1996) “Will Canada unravel?”, en Foreign affairs, September-October 1996. Volume 75. Number 5: 97-109.

Chan, Raymond (1997) "Canada and Asia Pacific", enAsia Pacific face-off, Canada among nations. Carlton University Press: 105-118.

LaFeber, Walter (1989) The American Age. Norton \& Company: London.

Minden, Karen, Nicole Gallant y Paul Irwin (1997) "Canada's role in APEC", en Asia Pacific face-off, Canada among nations. Carlton University Press: 119-144.

Stephenson, Brian J. R. (2000) “Too close to the americans, too far from the Americas: A liberal policy towards the hemisphere", en Vanishing borders, Canada among nations. Oxford University Press: 223-246. TI: 